\title{
Antimicrobial activity of spherical silver nanoparticles prepared using a biocompatible macromolecular capping agent: evidence for induction of a greatly prolonged bacterial lag phase
}

Peter Irwin ${ }^{1 *}$, Justin Martin ${ }^{1,2}$, Ly-Huong Nguyen ${ }^{1}$, Yiping $\mathrm{He}^{1}$, Andrew Gehring ${ }^{1}$, Chin-Yi Chen ${ }^{1}$

\begin{abstract}
Background: We have evaluated the antimicrobial properties of Ag-based nanoparticles (Nps) using two solid phase bioassays and found that 10-20 $\mu \mathrm{L}$ of 0.3-3 $\mu \mathrm{M}$ keratin-stabilized Nps (depending on the starting bacterial concentration $=C_{1}$ ) completely inhibited the growth of an equivalent volume of $\mathrm{ca}$. $10^{3}$ to $10^{4}$ colony forming units per $\mathrm{mL}$ (CFU mL ${ }^{-1}$ ) Staphylococcus aureus, Salmonella Typhimurium, or Escherichia coli O157:H7 on solid surfaces. Even after one week at $37^{\circ} \mathrm{C}$ on solid media, no growth was observed. At lower $\mathrm{Np}$ concentrations $(=[\mathrm{Np}]$ s), visible colonies were observed but they eventually ceased growing.
\end{abstract}

Results: To further study the physiology of this growth inhibition, we repeated these experiments in liquid phase by observing microbial growth via optical density at $590 \mathrm{~nm}(\mathrm{OD})$ at $37^{\circ} \mathrm{C}$ in the presence of a $[\mathrm{Np}]=0$ to $10^{-6} \mathrm{M}$. To extract various growth parameters we fit all OD[t] data to a common sigmoidal function which provides measures of the beginning and final OD values, a first-order rate constant ( $k$ ), as well as the time to calculated 1/2maximal OD $\left(t_{m}\right)$ which is a function of $C_{1}, k$, as well as the microbiological lag time $(T)$.

Performing such experiments using a 96-well microtitre plate reader, we found that growth always occurred in

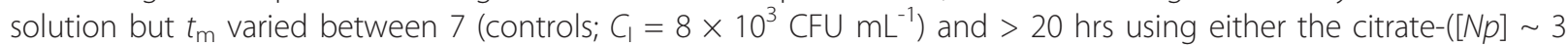
$\left.\times 10^{-7} \mathrm{M}\right)$ or keratin-based $\left([\mathrm{Np}] \sim 10^{-6} \mathrm{M}\right) \mathrm{Nps}$ and observed that $\left\{\partial \mathrm{t}_{\mathrm{m}} / \partial[\mathrm{Np}]\right\}_{\text {citrate }} \sim 5 \times 10^{7}$ and $\left\{\partial \mathrm{t}_{\mathrm{m}} / \partial[\mathrm{Np}]\right\}_{\text {keratin }} \sim$ $10^{7} \mathrm{hr} \cdot \mathrm{L} \mathrm{mol}^{-1}$. We also found that there was little effect of Nps on S. aureus growth rates which varied only between $k=1.0$ and $1.2 \mathrm{hr}^{-1}\left(1.1 \pm 0.075 \mathrm{hr}^{-1}\right)$. To test the idea that the Nps were changing the initial concentration $\left(C_{1}\right)$ of bacteria (i.e., cell death), we performed probabilistic calculations assuming that the perturbations in $t_{m}$ were due to $C_{1}$ alone. We found that such large perturbations in $t_{m}$ could only come about at a $C_{1}$ where the probability of any growth at all was small. This result indicates that much of the $\mathrm{Np}$-induced change in $t_{m}$ was due to a greatly increased $T$ (e.g., from ca. 1 to 15-20 hrs). For the solid phase assays we hypothesize that the bacteria eventually became non-culturable since they were inhibited from undergoing further cell division ( $T>$ many days).

Conclusion: We propose that the difference between the solid and liquid system relates to the obvious difference in the exposure, or residence, time of the Nps with respect to the bacterial cell membrane inasmuch as when small, Np-inhibited colonies were selected and streaked on fresh (i.e., no Nps present) media, growth proceeded normally: e.g., a small, growth-inhibited colony resulted in a plateful of typical S. aureus colonies when streaked on fresh, solid media.

* Correspondence: peter.irwin@ars.usda.gov

${ }^{1}$ Molecular Characterization of Foodborne Pathogens Research Unit, Eastern Regional Research Center, Agricultural Research Service, U. S. Department of

Agriculture, 600 East Mermaid Lane, Wyndmoor, PA 19038 USA

Full list of author information is available at the end of the article 


\section{Background}

In his famous and often cited talk given to the American Physical Society in 1959, Richard Feynman challenged scientists across all disciplines to consider the possibilities that could be achieved by miniaturization and atomic level control. In the ensuing fifty years, significant progress has been made to this end, affording scientists the ability to reproducibly create nanometersized inorganic structures including: spheres [1,2], wires [3], rods [3], tubes [3], belts [3], prisms [4-8], dendrimers [9], and many others [10]. As the chemical and physical properties of a nanomaterial are intimately linked to its size and shape, significant effort is, and has, been placed toward the syntheses of novel nanomaterials [11]. The ability to modify physical and chemical properties such as light scattering, absorption and emission, magnetic properties, electrical properties and others toward a specific application have made inorganic nanomaterials suitable for a wide variety of applications. Traditionally, these applications have included sensors, catalysis, electronics, surface enhanced Raman spectroscopy, biology and diagnostic imaging [1,12-14].

Recently, there has been a great deal of interest surrounding the discovery that silver nanoparticles ( $N p s$ ) are significantly more effective antimicrobial agents in terms of the minimum effective concentration than their $\mathrm{Ag}^{+}$counterparts [15]. This enhancement in relative antimicrobial activity has led researchers to develop their use in conjunction with medical products [16], their fixation on textiles [17-20] and other materials to prevent microbial growth or infections. Thus, one of the greatest challenges in integrating silver $\mathrm{Nps}$ with commercial products is attaining proper adhesion and functionality throughout the lifetime of the treated product. Unfortunately, we have found that the adhesion of the well-characterized citrate-stabilized silver $N p$ s to textiles to be poor. Furthermore, many of the options available for functionalizing the surfaces of textiles such as chemical treatments or cold plasma treatments degrade the material or affect some of their desirable intrinsic properties. To overcome such $N p$ limitations, we have been exploring the use of biocompatible protein stabilizers such as keratin to allow for facile attachment of the nanomaterial to textile surfaces through gentle heat or enzymatic processes. This process produced discrete spherical silver $N p$ s with a diameter of $3.4 \pm 0.74 \mathrm{~nm}$ that could be freeze-dried and easily re-suspended in water without ultrasonication and without significant aggregation. As this size distribution is in agreement with that obtained by Mirkin et al. [6] in their wellknown synthesis of citrate-stabilized Nps $(4.2 \pm 0.9 \mathrm{~nm})$, an opportunity was presented to study the effect of the keratin capping agent and the process of freeze drying/ re-suspension on the silver $N p$ 's ability to act as an antimicrobial agent. To the best of our knowledge, very little is known about the effect of macromolecular stabilizers on antimicrobial properties and microbial growth kinetics when encapsulating silver $N p$ s of similar size and shape [21], nor is the effect of processing the particles via freeze drying well-known. The importance of understanding the impact that a $N p$ stabilizer has on antimicrobial properties is highlighted in a recent study by Elechiguerra and coworkers [13] where silver Nps were prepared using three different protocols. Their results showed that $N p \mathrm{~s}<10 \mathrm{~nm}$ selectively bound to a glucagon-like peptide (glp20) to inhibit HIV-1 and noted that there was a difference in efficacy between the three capping technologies. These authorities suggest that the differences in antimicrobial effectiveness between silver $N p$ s capped with polyvinylpyrrolidone (PVP), foamy carbon and bovine serum albumin (BSA) may be due to the manner in which the Nps interact with the stabilizer. In the case of a foamy carbon matrix, they believe the Nps are virtually free, while for PVP and BSA, the Nps were believed to be tethered to the protein and encapsulated, resulting in their slightly reduced antimicrobial efficacy. In addition to stabilizer/surface interaction, the actual arrangement of silver atoms on the $N p$ surface may be important. In a recent study, Pal et al. [22] suggest that specific surfaces may be important for observing efficacy (e.g., the 111 surface: where the surface plane intersects the $x-, y-$ and $z$ - axes at the same value).

In this study, we investigate the growth kinetics and inhibition of one Gram-positive (Staphylococcus aureus) and two Gram-negative bacteria (Escherichia coli O157: H7 and Salmonella enterica serogroup 'Typhimurium' = Salmonella Typhimurium) in the presence of both citrate-stabilized and keratin-capped $N p$ s at various concentrations using a real-time spectrophotometric assay (i.e., growth-related behavior in aqueous media). We also investigate the effect of freeze-drying and resuspension on Escherichia coli and Salmonella Typhimurium. For comparison purposes we performed two solid-state Petri plate-based assays (i.e., behavior on solid media).

\section{Results and Discussion}

\section{Inhibition of S. aureus Growth on Solid Media}

Table 1 shows spread plate colony count data resulting from an inoculum of $500 \mu \mathrm{L}$ of $S$. aureus (i.e., a $10^{-4}$ dilution of an overnight culture $=10^{-4} \times C_{0}=C_{\mathrm{I}} \sim 6 \times$ $\left.10^{4} \mathrm{CFU} \mathrm{mL} \mathrm{mL}^{-1}\right)$ being dispersed across standard $\left(80 \mathrm{~cm}^{2}\right)$ Brain Heart Infusion (BHI) Petri plates. After drying the plates, $10 \mu \mathrm{L}$ of various concentrations of freeze-dried keratin-capped silver $N p$ s were applied drop-wise to the surface using a 6-channel pipette (i.e., 6 observations per region) across 4 regions per spread plate. After overnight growth at $37^{\circ} \mathrm{C}$, we saw that there were distinctive 
Table 1 Spread plate growth of Staphylococcus aureus on solid media in the presence of various $\mathrm{Np}$ concentrations

\begin{tabular}{|c|c|c|c|c|c|c|}
\hline \multirow[b]{2}{*}[Np]{$(\mathrm{nM})$} & \multicolumn{4}{|c|}{$C F U \mathrm{~cm}^{-2}$} & \multirow[b]{2}{*}{$\bar{x} \pm s$} & \\
\hline & Region: 1 & 2 & 3 & 4 & & \\
\hline 2903 & 22 & 30 & 35 & 6 & $23 \pm 13$ & $a$ \\
\hline 2322 & 58 & 67 & 75 & 42 & $61 \pm 14$ & $b$ \\
\hline 1742 & 118 & 61 & 127 & 82 & $97 \pm 30$ & $b$ \\
\hline 1161 & 148 & 116 & 126 & 83 & $118 \pm 27$ & $b$ \\
\hline 290 & 325 & 234 & 287 & 380 & $307 \pm 62$ & c \\
\hline 145 & 321 & 327 & 327 & 329 & $326 \pm 3$ & c \\
\hline 29 & 399 & 355 & 479 & 414 & $412 \pm 51$ & $d$ \\
\hline 0 & 314 & 349 & 303 & 361 & $332 \pm 28$ & c \\
\hline
\end{tabular}

Averages associated with different letters are significantly different at the $p=0.05$ level (ANOVA \& multiple range test performed on log-transformed data). The size of the spotted $N p$ areas was approximately $0.255 \mathrm{~cm}^{2}$. The lowest effective concentration provides a $\mathrm{Np}$ :CFU ratio of $\mathrm{ca} .10^{11}$. This calculation is assuming a $[\mathrm{Np}]-0 \mathrm{CFU}$ intersection occurring at about $2 \times 10^{13}$ Nps (in $10 \mu \mathrm{L}$ ) and 375 CFU per $0.255 \mathrm{~cm}^{2}$ drop area.

circular areas $\left(\sim 0.3 \mathrm{~cm}^{2}\right)$ of limited S. aureus growth: $i$. $e$., at the higher $[N p] \mathrm{s}$, what colonies existed were much smaller than those observed growing outside these zones. Upon counting what colonies appeared, we saw that the counts decreased linearly with $\log _{10}[N p]$. Analysis of variance and a multiple range test were performed (Methods Section); any 2 averages were considered significantly different at the $p=0.05$ level if the absolute value of their difference was $>q_{0.05} s_{\bar{x}}$. We also noted that the small colonies within the zone of growth inhibition did not appear to grow further while those outside the inhibition zone of each $N p$ drop grew into each other forming an almost contiguous colony. Interestingly, after several days of no apparent growth, when one of these growth-inhibited colonies was sampled and streaked on fresh media (i.e., in the absence of silver $N p$ s), there was a proliferation of normal colony growth. This result implies that the continued presence of the keratin-capped silver $N p$ s on the plate's surface limited further cell division. Table 1 also indicates that a ratio of at least $10^{11} \mathrm{~Np}$ : $\mathrm{CFU}$ is required to show complete growth inhibition. Similar results were observed for both Salmonella Typhimurium and $E$. coli O157:H7 (data not shown).

In order to improve the experimental variation, we performed a drop plate-based assay (Table 2) that would provide better control for dispensing the test organism on the plate's surface. This protocol involved first placing twenty $(4 \times 5$ format using a 4 -channel pipette) evenly spaced $20 \mu \mathrm{L}$ bacteria-laden drops $\left(\sim 10^{-5} \times C_{0}=\right.$ $C_{\mathrm{I}}=2 \times 10^{3} \mathrm{CFU} \mathrm{\textrm {mL } ^ { - 1 }}$; BHI-diluted) onto each of 2 plates. Then, after drying, $4 \times 20 \mu \mathrm{L}$ of each $N p$ concentration (up to $c a .0 .8 \mu \mathrm{M}$ ) was carefully added on top of each air-dried, organism-loaded spot. Growth at $37^{\circ} \mathrm{C}$ was checked daily for at least a week. Each drop plate set was replicated thrice using different $S$. aureus
Table 2 Drop plate growth of Staphylococcus aureus on solid media in the presence of equivalent volumes (20 $\mu \mathrm{L})$ of various $N p$ concentrations

\begin{tabular}{|c|c|c|c|c|c|c|}
\hline \multirow[b]{2}{*}[Np]{$(n M)$} & \multicolumn{3}{|c|}{ CFU $\mathrm{mL}^{-1}$} & \multirow[b]{2}{*}{$\bar{x} \pm s$} & \multirow[b]{2}{*}{$\log$} & \multirow[b]{2}{*}{ Linear } \\
\hline & Exp: 1 & 2 & 3 & & & \\
\hline 783 & 0 & 0 & 0 & 0 & & \\
\hline 587 & 0 & 0 & 0 & 0 & & $a$ \\
\hline 392 & 0 & 0 & 0 & 0 & & $a$ \\
\hline 196 & 88 & 25 & 88 & $67 \pm 36$ & $a$ & $a$ \\
\hline 157 & 375 & 125 & 288 & $263 \pm 127$ & $b$ & $a b$ \\
\hline 117 & 463 & 413 & 438 & $438 \pm 25$ & $b c$ & $a b$ \\
\hline 78 & 763 & 450 & 725 & $646 \pm 171$ & $c$ & $b$ \\
\hline 39 & 1638 & 1050 & 1813 & $1500 \pm 399$ & $d$ & c \\
\hline 20 & 2350 & 1388 & 1913 & $1883 \pm 482$ & $d$ & $c d$ \\
\hline 0 & 2163 & 1913 & 2050 & $2042 \pm 125$ & $d$ & $d$ \\
\hline
\end{tabular}

Averages associated with different letters are significantly different at the $p=0.05$ level (ANOVA \& multiple range test performed on both log-transformed \{null values were excluded\} and non-log-transformed or linear data). The lowest effective concentration ( $392 \mathrm{nM}$ ) provides a $\mathrm{Np}$ :CFU ratio of ca. $10^{11}$.

cultures and dilutions (Methods Section). Multiple range tests were performed on both the linear and Log-transformed data. In these experiments we saw that no $S$. aureus colonies developed when ca. 0.4 to $0.8 \mu \mathrm{M}$ keratin-capped $N p$ s were applied. At lower $[N p]$ s colony counts were linearly related $([N p] \geq 0.2 \mu \mathrm{M})$ with $\log _{10}$ $[N p]$. As before (Table 1), the observed colonies that formed were small and appeared to remain in stasis, or only grew at a much reduced rate, relative to those colonies forming in the control (i.e., $[N p]=0)$ areas or at much lower $[N p]$ s.

Interestingly, at the outer boundaries of each $N p$ drop there was a continuous ring of $S$. aureus growth which never impinged within the well-defined zones of inhibition. These data indicate that the maximum keratinbased silver $N p$ growth inhibition was observed at a $N p$ : CFU ratio of about $10^{11}$ which is similar to that observed previously (Table 1). Growth-inhibited colonies when streaked on fresh media grew normally, however, after several weeks of no observable growth on the original $N p$-treated regions, spread plating of one of these small colonies on fresh media resulted in no growth. This observation indicates that these cells were either moribund, or, more likely, dead.

\section{Inhibition of Bacterial Growth in Liquid BHI}

Table 1 and 2 clearly demonstrated that on a solid matrix, where both bacteria and $N p$ s have limited motion, the keratin-based silver Nps completely inhibited S. aureus growth. Would a similar effect occur in a liquid where bacteria and $N p$ s can both move freely? To answer this question and potentially gain some insight into the physiology involved, OD-based growth assays [23] were performed and a large set of treatments (e.g., 
11 levels of $[N p] \mathrm{s}\{5,10,15,20,25,30,35,40,45$, and $50 \mu$ g per well $\cong 0.26,0.52,0.78,1.0,1.3,1.6,1.8,2.1$, 2.3 , and $2.6 \mu \mathrm{M}\}+1$ negative control +3 keratin only controls all in BHI; $\left.C_{\mathrm{I}}=8.3 \times 10^{3} \mathrm{CFU} \mathrm{mL} \mathrm{mL}^{-1} \pm 13 \%\right)$ were distributed in a 96 -well microtitre plate. The covered plate was equilibrated at $37^{\circ} \mathrm{C}$ for a short period of time and OD $(\lambda=590 \mathrm{~nm})$ measured after shaking every $14 \mathrm{~min}$ for over $25 \mathrm{hrs}$. From the OD[t] truncated data arrays, Eq. 1 (all equations are discussed in the Methods section) was used and the various growth parameters ( $k$ and $t_{\mathrm{m}}$ ) were determined.

Analysis of variance was performed on both parameters and we found that there was no statistically significant effect of the various $[N p]$ s on $k\left(F_{13,26}=3.6\right.$; $k \pm q_{0.05} s_{\bar{x}} \div 2=1.1 \pm 0.075 \mathrm{hr}^{-1}$; doubling time $=\tau=$ $38 \pm 2.6 \mathrm{~min})$. However, there was a significant effect on $t_{\mathrm{m}}$ (Table 3 ), which is the incubation time to $1 / 2$ maximal $\mathrm{OD}\left(\mathrm{OD}_{\mathrm{F}} \div 2\right.$, Eq. 1). It is important to keep in mind that by the time we begin to observe an increase in OD, about 10-15 doublings will have occurred. Because of this fact, the OD-based lag time $\left(t_{\mathrm{m}}:\right.$ Eq. 1) [24] is related to the starting cell concentration $\left(C_{\mathrm{I}}\right)$, the rate of growth $(k)$, as well as the microbiological lag time $(T)$ [23]. These interrelationships are fully developed in Eq. 5.

Since the apparent effect $N p$ s have on $t_{\mathrm{m}}$ could also result from a change in $C_{\mathrm{I}}$ (via cell death), we have also estimated the probability $\left(P_{+}\right.$, Eq. 6) for any growth

\begin{tabular}{|c|c|c|c|c|c|c|c|c|}
\hline \multicolumn{2}{|c|}{ per well } & \multicolumn{5}{|c|}{$t_{\mathrm{m}}(\mathrm{hrs})$} & \multirow[b]{2}{*}{$P_{+}$, avg } & \multirow[b]{2}{*}{$\begin{array}{c}T_{\text {corr, av }} \\
\text { (hrs) }\end{array}$} \\
\hline $\begin{array}{l}\mu \mathrm{g} \\
N p\end{array}$ & $\underset{\text { keratin }}{\mu \mathrm{g}}$ & $\begin{array}{c}\text { Exp: } \\
1\end{array}$ & 2 & 3 & avg & & & \\
\hline 0 & 0 & 6.74 & 6.13 & 6.89 & 6.59 & $a$ & 1 & 1.11 \\
\hline 5 & 0 & 8.72 & 7.18 & 8.52 & 8.14 & $a$ & 1 & 2.66 \\
\hline 10 & 0 & 13.3 & 11.4 & 12.3 & 12.3 & $b$ & 0.798 & 6.83 \\
\hline 15 & 0 & 13.4 & 12.8 & 13.9 & 13.4 & $b$ & 0.644 & 7.91 \\
\hline 20 & 0 & 15.7 & 14.7 & 15.6 & 15.4 & $c$ & 0.0995 & 9.89 \\
\hline 25 & 0 & 16.8 & 15.7 & 16.3 & 16.2 & c & 0.100 & 10.8 \\
\hline 30 & 0 & 19.3 & 18.2 & 17.8 & 18.4 & $d$ & 0.00551 & 13.0 \\
\hline 35 & 0 & 23.5 & 20.3 & 21.4 & 21.7 & $e$ & 0.00163 & 16.3 \\
\hline 40 & 0 & 24.9 & 21.7 & 24.8 & 23.8 & $f$ & 0.0000628 & 18.3 \\
\hline 45 & 0 & 27.1 & 26.9 & 27.3 & 27.1 & $g$ & 0.00000288 & 21.6 \\
\hline 50 & 0 & 27.6 & 28.4 & 26.8 & 27.6 & $g$ & 0.00000165 & 22.1 \\
\hline 0 & 10 & 6.65 & 6.11 & 6.89 & 6.55 & $a$ & 1 & 1.08 \\
\hline 0 & 25 & 6.95 & 6.20 & 6.69 & 6.62 & $a$ & 1 & 1.14 \\
\hline 0 & 50 & 6.69 & 6.00 & 6.73 & 6.47 & $a$ & 1 & 1.00 \\
\hline
\end{tabular}

Averages associated with different letters are significantly different at the $p=$ 0.05 level. There is no significant effect of the keratin alone on $t_{\mathrm{m}}$. The $5 \mathrm{\mu g}$ $\mathrm{Np}$ level is equivalent to ca. $2.6 \times 10^{-7} \mathrm{M}$. occurring in the 96-well plates assuming only changes in $C_{\mathrm{I}}$ with a $T$ fixed at $1 \mathrm{hr}$. Therefore, in essence, $P_{+}$is the probability that the observed changes in $t_{\mathrm{m}}$ could be due to perturbations in the $C_{\mathrm{I}}$ in the presence of the Nps. These data are also presented in Table 3 and demonstrate that a $t_{\mathrm{m}}$ beyond about 7-9 hrs is highly unlikely to be due to changes in initial bacteria concentration. We calculated a corrected $T\left(T_{\text {corr }}=T-T_{\mathrm{C}}+1\right)$ by assuming that the controls $\left(T_{\mathrm{C}}=1.1,1.1,1.1\right.$, and $1.0 \mathrm{hrs}$ for $0+0,0+10,0+25,0+50$ control combinations \{i.e., $\mu \mathrm{g} N p+\mu \mathrm{g}$ keratin per well\}, respectively, Table 3 ) have a $T$ of $\sim 1 \mathrm{hr}$ which is the approximate true microbiological lag time in unperturbed systems $(T$ $=1.4 \pm 0.49 \mathrm{hr}$ ). When a $T_{\text {corr }}$ was estimated, we saw a linear relationship with $[N p]: \partial T_{\text {corr }} / \partial[N p] \sim 8.3 \times 10^{6}$ $\mathrm{L} \cdot \mathrm{hr} \mathrm{mol}^{-1}[ \pm 3 \%], T_{\text {corr, }}[N p]=0 \sim 1.1 \pm 0.47 \mathrm{hr}, \mathrm{r}^{2}=$ 0.99 . To the best of our knowledge, there are no known treatments which can cause such a clear, and relatively predictable, perturbation in bacterial lag times. Thus, in solution, the Nps can induce a $20 \mathrm{hr}$ increase in the microbiological lag time but eventually all treatments grow to a normal $\mathrm{OD}_{\mathrm{F}}$ level (Methods section). We propose that the same physiological effect is occurring on solid surfaces but, because the $T$ values are so long, the bacteria eventually expire or go into deep stasis.

For comparison purposes, we investigated the relative efficacy of keratin- and citrate-capped silver nanoparticles. Figure 1 displays both $t_{\mathrm{m}^{-}}(\mathbf{1 A})$ and $T_{\text {corr }}$-based (1B) averages calculated from $S$. aureus (3 cultures $=3$ blocks or replicates) microplate growth assays using either citrate- $(\bullet)$ or keratin-capped $(\boldsymbol{\Delta}) \mathrm{Np}$-treated $\mathrm{BHI}$ at $37^{\circ} \mathrm{C}$. Both $N p$ treatments had a linear relationship with respect to their effect on either $t_{\mathrm{m}}$ (citrate: $\partial t_{\mathrm{m}} / \partial[N p] \sim 4.9 \times 10^{7} \mathrm{~L} \cdot \mathrm{hr} \mathrm{mol}{ }^{-1}[ \pm 4 \%], \mathrm{r}^{2}=0.99$; keratin: $\partial t_{\mathrm{m}} / \partial[N p] \sim 1.2 \times 10^{7} \mathrm{~L} \cdot \mathrm{hr} \mathrm{mol}^{-1}[ \pm 5 \%], \mathrm{r}^{2}=$ 0.98 ) or $T_{\text {corr }}$ (citrate: $\partial T_{\text {corr }} / \partial[N p] \sim 5.5 \times 10^{7} \mathrm{~L} \cdot \mathrm{hr}$ $\mathrm{mol}^{-1}[ \pm 8 \%], \mathrm{r}^{2}=0.95$; keratin: $\partial T_{\mathrm{corr}} / \partial[N p] \sim 1.1 \times$ $\left.10^{7} \mathrm{~L} \cdot \mathrm{hr} \mathrm{mol}^{-1}[ \pm 4 \%], \mathrm{r}^{2}=0.98\right)$ as a function of $[N p]$. At low $[N p] \mathrm{s}$, both citrate- and keratin-stabilized $N p$-treated cultures asymptote to similar values of $t_{\mathrm{m}}$ $\left(t_{\mathrm{m},[N p]=0}=5.7 \pm 0.29\right.$ and $6.2 \pm 0.33 \mathrm{hr}$ for citrateand keratin-based Ag Nps, respectively) or $T_{\text {corr }}\left(T_{\text {corr, }}\right.$ $[N p]=0=0.12 \pm 0.67$ and $1.1 \pm 0.26 \mathrm{hr})$. Differing from the keratin-capped Ag $N p$ behavior we saw previously (i.e., on semi-solid surfaces: Table 1 and 2), a greater $N p$ :CFU ratio was required $\left(>10^{12}\right.$ ), in order to achieve a maximum growth inhibition effect. From the ratios of slopes (either $\partial t_{\mathrm{m}} / \partial[N p]$ or $\partial T_{\text {corr }} / \partial[N p]$ ) we saw that the citrate-stabilized Ag Nps were about 4-5fold more effective than the keratin-based $N p$ at an equivalent $C_{\mathrm{I}}$. This difference illustrates the value of understanding the effect that a $N p$ stabilizer has on antimicrobial properties since it is known that different-sized stabilizers can result in different efficiencies 


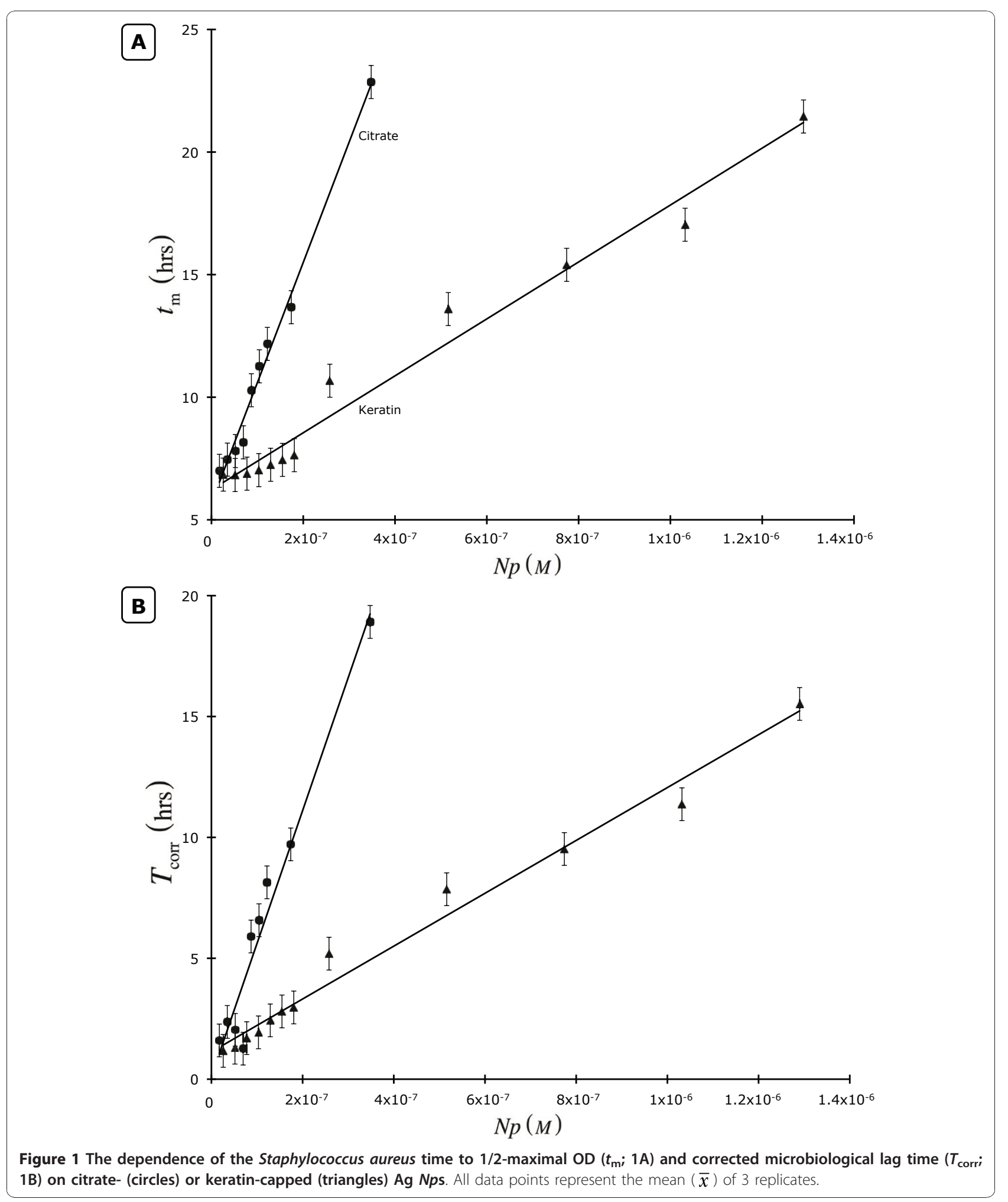


[13]. Our results in Figure 1 indicate that a similar stabilizing agent size-based phenomenon may be occurring with the keratin-capped Nps. It is also possible that the keratin-stabilized Ag Nps have an activity distribution where ca. $20 \%$ are as fully active as citratebased particles while the rest are completely inactive due to excessive imbedding of the crystalline silver $N p$ assembly within the capping protein's structure.

\section{Anomalous $\mathrm{Np}$ activity differences in fresh $\mathrm{BH}$}

During the course of this study, we noticed an inexplicable change in the response of $S$. aureus to keratincapped Nps, which appeared to be coincidental with a change in liquid media: i.e., from that which was stored to that which was freshly made from the same lot of BHI powder. Because of this we performed another set of experiments (Figure 2) to specifically clarify the effects of both media (2A: fresh BHI; 2B: stored BHI) as well as initial $S$. aureus concentration $\left(C_{\mathrm{I}}\right)$ on the growth response to keratin-capped $N p$ s. Because $C_{\mathrm{I}}$ has such a strong effect on $t_{\mathrm{m}}$ [24], only $T_{\text {corr }}$ averages, calculated from $3 \mathrm{BHI}$-diluted overnight cultures $\left(C_{0}\right)$ used to generate each initial concentration of $S$. aureus, are reported. To do this, 4 dilutions (the dilution factors, $\Phi_{\mathrm{I}},=10^{-3}[\bullet], 10^{-4}[\mathbf{\Delta}], 10^{-5}[\bullet]$, and $\left.10^{-6}[\mathbf{\bullet}]\right)$ from 3 separate $S$. aureus overnight cultures grown in freshly prepared BHI $\left(C_{0}=8.8 \times 10^{8} \mathrm{CFU} \mathrm{mL} \mathrm{mL}^{-1}[ \pm 10 \%]\right)$ were created $\left(C_{\mathrm{I}}=C_{0} \Phi_{\mathrm{I}}\right)$, distributed into a 96-well plate and 8 levels of keratin-stabilized $[N p]$ s were introduced. Similar to what we have referred to previously (Table 1 and 2, Figure 1), we noted that a large $N p$ :CFU ratio

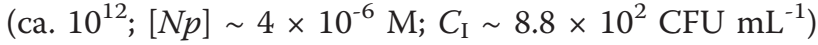
was required to achieve the maximum growth perturbation effect (largest $T_{\text {corr }} \sim 15$ and 24 hrs for fresh or stored BHI, respectively). There were other clear-cut effects of the media aging on S. aureus' apparent lag phase response to keratin Nps inasmuch as there was almost no significant lag time response to the presence of lower $[N p]$ levels relative to the same culture diluted with stored BHI.

Lastly, we sought to determine the relative efficacy of keratin-capped Ag Nps (in fresh BHI) with respect to Gram-negative bacilli. Figure 3 shows $T_{\text {corr }}$ data determined from growth studies using a $C_{\mathrm{I}} \sim 3 \times 10^{3} \mathrm{CFU}$ $\mathrm{mL}^{-1}$ Salmonella Typhimurium (closed symbols) or $E$. coli O157:H7 (open symbols), both of which are pathogenic. In these experiments we also characterized these bacteria for their response to $N p$ s that were either freeze-dried (triangles) and then re-suspended in fresh $\mathrm{BHI}$ or those that were stored in their original aqueous medium (diamonds). As in previous work there was an approximately linear relationship between $T_{\text {corr }}$ and $[N p]\left(e . g ., \partial T_{\text {corr }} / \partial[N p] \sim 5.6 \times 10^{6} \mathrm{~L} \cdot \mathrm{hr} \mathrm{mol}^{-1}[ \pm 6 \%]\right.$, $\left.T_{\text {corr },[N p]=0} \sim 0.62 \pm 0.34 \mathrm{hr}, \mathrm{r}^{2}=0.90\right)$. The lag time data presented in Figure 3 indicates that there was not any consistent overall loss of $N p$ antimicrobial activity upon freeze drying. Compared to the keratin-based Ag $N p$ antimicrobial activity (i.e., $N p$ :CFU ratio for maximal activity ca. $10^{12}$ ) we saw previously with $S$. aureus, the $N p$ :CFU ratio which resulted in maximal activity was ca. $10^{11}$. Thus these particular Gram-negative organisms appear to be more sensitive than $S$. aureus to the keratin-based Ag Nps.

\section{Conclusions}

In this work we have evaluated the antimicrobial properties of a biocompatible macromolecular capping agent-based (keratin) Ag Np using both solid- and solution-state media assays. We found that on solid surfaces, 10-20 $\mu \mathrm{L}$ of 0.3-3 $\mu \mathrm{M}$ keratin-based Nps completely inhibited the growth of Staphylococcus aureus and, after several weeks at $37^{\circ} \mathrm{C}$, no further growth was observed. At lower $N p$ concentrations, intermediate levels of colony formation occurred (less than the control) but the colonies ceased growing beyond a certain small size. When these small colonies were selected and streaked on fresh media without Nps, growth proceeded normally. These results imply that further cell division is limited due to the continued presence of Ag Nps on the solid surface.

In liquid phase we found that growth always occurred but the $t_{\mathrm{m}}$ varied between 7 and $>20$ hrs (assuming a constant $\left.C_{\mathrm{I}}\right)$ using either the citrate- $\left([N p] \sim 3 \times 10^{-7}\right.$ $\mathrm{M})$ or keratin-based $\left([\mathrm{Np}] \sim 10^{-6} \mathrm{M}\right) \mathrm{Nps}$. We discovered that this delay was not related to the effect that $N p$ s had on $S$. aureus $k$ values. To test the possibility that the $N p$ s were effectively changing $C_{\mathrm{I}}$ bacteria via cell death, we performed probabilistic calculations assuming that the perturbations in $t_{\mathrm{m}}$ were due to $C_{\mathrm{I}}$ alone (i.e., with a fixed $T$ ).

We found that our observed large perturbations in $t_{\mathrm{m}}$ could only come about at concentrations where the probability for any growth occurring at all was small. This result indicates that much of the $N p$-induced change in $t_{\mathrm{m}}$ was due to a greatly increased value for the true microbiological lag time ( $T$ increased from $\sim 1$ to $>15-20 \mathrm{hrs}$ ). In either solution or the solid state, a maximum perturbation was noticed only when the ratio of $[N p]: C_{\mathrm{I}}$ (on a particle:cell basis) was about $10^{11}-10^{12}$. We propose that the differences observed between the solid and liquid growth systems relates to obvious differences in the residence time of the Nps with respect to the bacterial cell membrane.

\section{Methods}

Scoured and carbonized wool fibers, $\sim 21 \mu \mathrm{m}$ in diameter, were obtained from the Bollman Hat Company, Adamstown PA. Silver nitrate, sodium citrate, sodium 


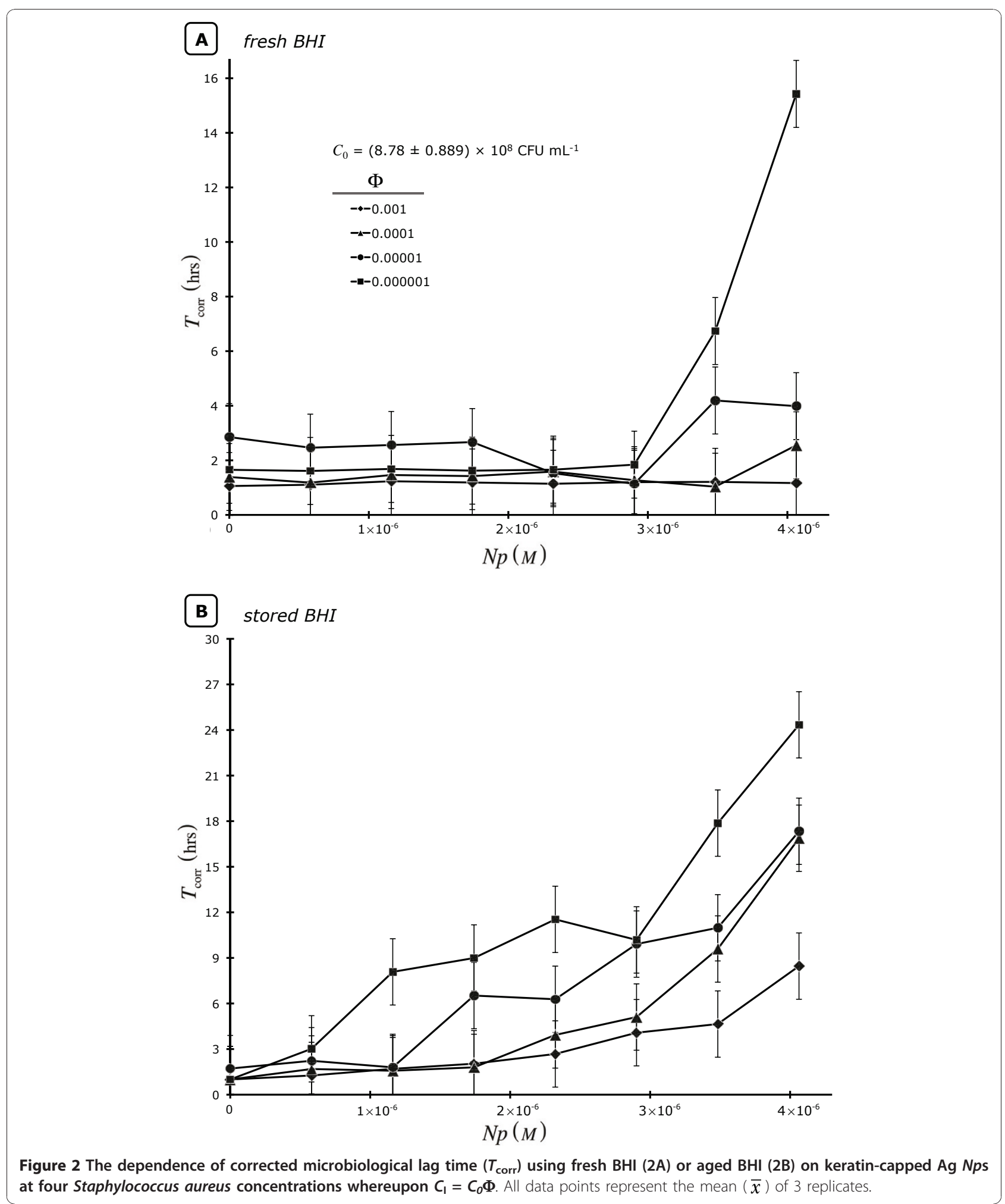

borohydride, sodium hydroxide, and methylene chloride were obtained from Sigma-Aldrich and used as received. 6,000-8,000 Da molecular weight cutoff Spectra Por dialysis tubing was obtained from VWR scientific and used as received. Deionized water was obtained using a Barnstead Nanopure filtration system. TEM images were collected using a Phillips CM12 Cryo system. UV-VIS measurements were recorded in solution using a Cary 


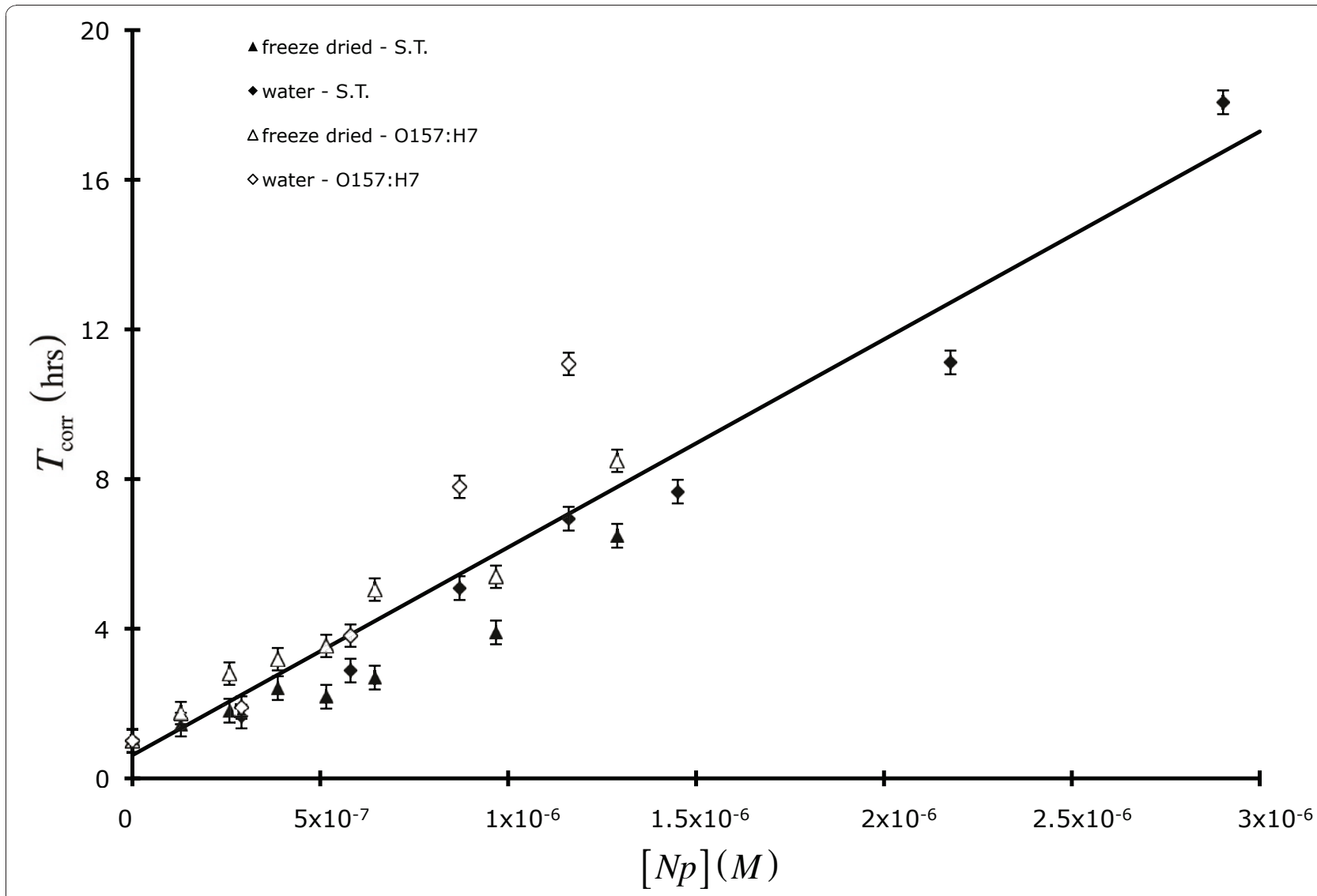

Figure 3 The dependence of corrected microbiological lag time $\left(T_{\text {corr }}\right)$ on either freeze-dried (triangles) or water-based (diamonds) keratin-capped Ag Nps for Salmonella Typhimurium (solid symbols) or E. coli 0157:H7 (open symbols). All data points represent the mean $(\bar{x})$ of 3 replicates.

50 Conc spectrometer, a Tecan Microplate Reader equipped with XFluor4SafireII software v4.62A (100 averages), a Perkin-Elmer HTS7000+ 96 well plate reader (used for bacterial growth data exclusively), and an Aviv instruments UV-VIS spectrophotometer model 14NT-UV-VIS.

\section{Preparation of keratin hydrolysate}

Keratin hydrolysates were prepared by taking cleaned and scoured wool and adding this to a $0.5 \mathrm{~N} \mathrm{NaOH}$ solution at $60^{\circ} \mathrm{C}$ for three hours. The hydrolyzed keratin was dialyzed through Spectra Por dialysis tubing with a 6,000-8,000 Da molecular weight cutoff. The water was changed three times during a 24 hour dialysis period. The hydrolyzed keratin was then lyophilized using a FTS Flexidry ${ }^{\mathrm{mi}}$ System. Upon addition of the protein, a change in the $\mathrm{pH}$ toward basic was observed.

\section{Preparation of colloidal keratin stabilized silver nanoparticles}

Stable colloidal Ag Nps were prepared by adding $0.1 \mathrm{~g}$ of the dried keratin hydrolysate to $100 \mathrm{~mL}$ of rapidly stirring deionized water. The $\mathrm{pH}$ of the system was adjusted to 8.5-8.9 using a dilute sodium hydroxide solution if necessary. After dissolution, $0.184 \mathrm{~g} \mathrm{(ca.} 10^{-3}$ mol) of silver nitrate was added to the stirring keratin solution and the $\mathrm{pH}$ was observed to change to approximately 6.7. In a separate vial, $0.0097 \mathrm{~g}$ (ca. $2.5 \times 10^{-3}$ mol) of sodium borohydride was measured and added to $5 \mathrm{~mL}$ of deionized water.

Exactly $1 \mathrm{~mL}$ of this solution was added dropwise to the rapidly stirring keratin/silver nitrate solution at room temperature over the course of 10 minutes. The solution changed from a clear to dark orange color and the final $\mathrm{pH}$ of the solution was measured to be 7.7. The particles were spun in a Cole-Parmer benchtop centrifuge $(\leq 3800 \mathrm{RPM})$ and the liquid fraction was removed with a glass Pasteur pipette. An identical amount of clean deionized water was added and this procedure was repeated at least three times. For lyophilization studies, the silver $N p$ suspension was lyophilized using a FTS Flexidry ${ }^{\mathrm{min}}$ System.

Figure 4 shows that the maximum OD occurs at $\lambda=$ $425 \pm 2.06 \mathrm{~nm}$ (average across 4 dilutions) which is due 


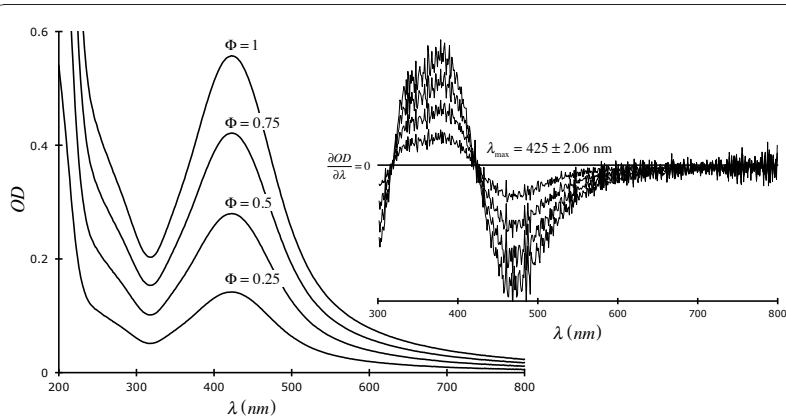

Figure 4 Absorbance and first derivative spectra of keratincapped Ag Nps at $\mathbf{4}$ dilutions. $\boldsymbol{\lambda}_{\text {max }}$ is an average of the 4 derivatives (at $\partial O D / \partial \lambda=0$ ).

to surface plasmon resonance, a feature common to sols of discrete inorganic Nps. The absorbance at shorter wavelengths is due to $\pi \rightarrow \pi^{*}$ and $n \rightarrow \pi *$ transitions from the keratin capping agent. $N p$ concentrations were determined spectroscopically according to a previously published procedure [25]. Using TEM, we established that our keratin-based Nps are spherical with a diameter $(d)$ normally-distributed (unimodal) about $d=3.4 \pm$ $0.74 \mathrm{~nm}(\mu \pm \sigma)$. Citrate-stabilized Ag Nps were prepared and rinsed according to a procedure published by various workers [4-8].

\section{Spread plate growth assay procedures}

For the spread plate assay $500 \mu \mathrm{L}$ of a $10^{-4}$ dilution (ca.

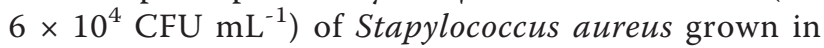
$\mathrm{BHI}$ broth overnight at $37^{\circ} \mathrm{C}$ was evenly spread over the entire surface of a $\mathrm{BHI}$ broth-based solid ( $2 \%$ agarose) media Petri plate $\left(\mathrm{ca} .80 \mathrm{~cm}^{2}\right)$ and allowed to dry 15 min in a microbiological hood to avoid surface contamination. After compete drying, various solutions (from ca. $10^{-7}$ to $3 \times 10^{-6} \mathrm{M}$ ) of the freeze-dried keratin Nps which had been suspended in sterile water were applied as $10 \mu \mathrm{L}$ drops to the plate: 6 drops per region $(6$ drops each were applied with a multiple channel pipette to the 2 middle and 2 exterior regions of the Petri dish; experiments were replicated this way to take into account the slight variability of spreading the bacterial suspension evenly) and 4 regions per plate in a randomized complete block experimental design where each "region" represents a separate "block". Areas of growth inhibition were measured and colonies were counted several times over the course of a week at $37^{\circ} \mathrm{C}$.

\section{Drop plate growth assay procedures}

For the sake of both precision and accuracy, we also performed a drop plate assay which consisted of applying $4 \times 5$ (i.e., 4 rows 5 columns) $20 \mu \mathrm{L}$ drops of $\sim 2 \times$

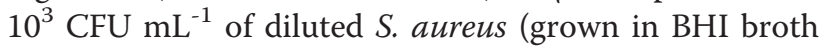
overnight at $37^{\circ} \mathrm{C}$ ) to each plate, making sure that a pipette tip mark indicated the center of each drop to locate where to dispense the $N p$ solution. After drying, $20 \mu \mathrm{L}$ of each $N p$ concentration (up to $c a .800 \mathrm{nM}$ ) was added on top of each air-dried, organism-loaded drop. Growth at $37^{\circ} \mathrm{C}$ was checked daily for at least a week. Each such experimental procedure was replicated thrice using a fresh culture.

\section{6-well microtitre plate growth assay procedures}

Dilutions using liquid growth media (BHI) as the diluent were made from refrigerated (at least one day and up to 2 weeks), stationary-phase Staphylococcus aureus (Gram-positive coccus), Salmonella Typhimurium (Gram-negative bacillus), or Escherichia coli O157:H7 (Gram-negative bacillus) cultures grown in BHI. The sterile BHI broth was either fresh $(<1$ month in the dark at room temperature) or the same medium which had been stored > 1 month. All media came from the same lot of starting material. Three hundred $\mu \mathrm{L}$ of each treatment combination ([Np] level and/or bacteria $C_{\mathrm{I}}$ ) were added to each well. Each specific bacterial concentration used is provided in Table or Figure legends. All freeze-dried keratin-capped $N p$ levels were created by diluting with BHI. In order to avoid water condensation which might interfere with absorbance readings, the interior surface of microplate covers were rinsed with a solution of $0.05 \%$ Triton X-100 in $20 \%$ ethanol and dried in a microbiological hood under UV light [24]. All calculations took into account the small dilution upon adding the various $N p$ solutions. A Perkin-Elmer HTS 7000+ 96-well plate reader was used for optical density (OD) measurements over time using: $\lambda=590 \mathrm{~nm}$; temp $=37^{\circ} \mathrm{C}$; time between points was either 10,12 or $14 \mathrm{~min}$ and 110 data points were always collected.

After completion of any OD with time growth experiment, a tab-delimited text file was generated and data pasted into a Microsoft Excel spreadsheet formatted to display the data arrays as individual well ODs at each time point $(\mathrm{OD}[\mathrm{t}])$. OD growth curves were then curve-fitted to Eq. 1 which is a well-known sigmoidal function used in various physiological studies $[23,26]$.

$$
\mathrm{OD}_{590}=\mathrm{OD}_{\mathrm{F}}+\frac{\mathrm{OD}_{\mathrm{I}}-\mathrm{OD}_{\mathrm{F}}}{1+\operatorname{Exp}\left[\left(\mathrm{t}-\mathrm{t}_{\mathrm{m}}\right) k\right]}
$$

In Eq. 1, $\mathrm{OD}_{\mathrm{I}}$ is the estimated initial optical density $(0.05-0.1), \mathrm{OD}_{\mathrm{F}}$ is the calculated final OD $(0.8-1.2), k$ is a first-order rate constant (doubling time $=\tau=\operatorname{Ln}[2]$ $\div k$ ), and $t_{\mathrm{m}}$ is the time to $\mathrm{OD}=\mathrm{OD}_{\mathrm{F}} \div 2$. The parameter $t_{\mathrm{m}}$ is also the time where the maximum in the first derivative of $\mathrm{OD}[\mathrm{t}]$ with time $\left(\partial_{t} \mathrm{OD}[\mathrm{t}]\right)$ occurs and indicates the center of symmetry of the fitted Eq. 
1. Typical OD[t] growth curves (S. aureus) are presented in Figure 5 which have been curve-fitted with Eq. 1. In this Figure, two growth curves $(\mathrm{OD}[\mathrm{t}]$ : open circles = negative control; closed circles $\sim 10^{-6} \mathrm{M}$ freeze-dried keratin Nps; $C_{\mathrm{I}}=$ starting bacteria concen-

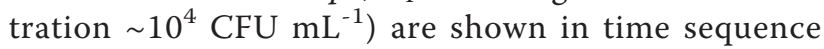
along with $\partial_{\mathrm{t}} \mathrm{OD}[\mathrm{t}]$ (triangle symbols). Notice that the calculated (from Eq. 1) $t_{m}$ s are approximately equivalent to the maxima in the $\partial_{t} \mathrm{OD}[\mathrm{t}]$ plots. In order to achieve the best fit we use only the OD[t] with time region which provides the most information (i.e., the exponential increase in $\mathrm{OD}[\mathrm{t}])$ and therefore have truncated all data and used only 5-10 points beyond the apparent $t_{\mathrm{m}}$ to fit to Eq. 1. Such data abbreviation has been shown to have only minor effects on the growth parameters [23]. Figure 5 also shows the beginning and ending points of data truncation. All curvefitting was performed using a Gauss-Newton algorithm on an Excel spreadsheet [27]. Eq. 1 appears to be generally useful with optically-based growth results since excellent fits were achieved when this equation was utilized to fit various $[23,28]$ bacterial growth data.

We have recently [23] shown that (E. coli) doubling time $(\tau)$ values from OD[t] data fitted to Eq. 1 agreed with those obtained from manual plate counting with time. All values of $k$ and $t_{\mathrm{m}}$ reported herein are derived from such curve-fitting. Of course, $t_{\mathrm{m}}$ can also be easily estimated from the $\mathrm{x}$-axis value where the center of symmetry in $\partial_{t} \mathrm{OD}[\mathrm{t}]$ occurs.

During the log phase of growth [29], the rate of change in bacterial concentration with respect to time can be represented by the simple differential equation

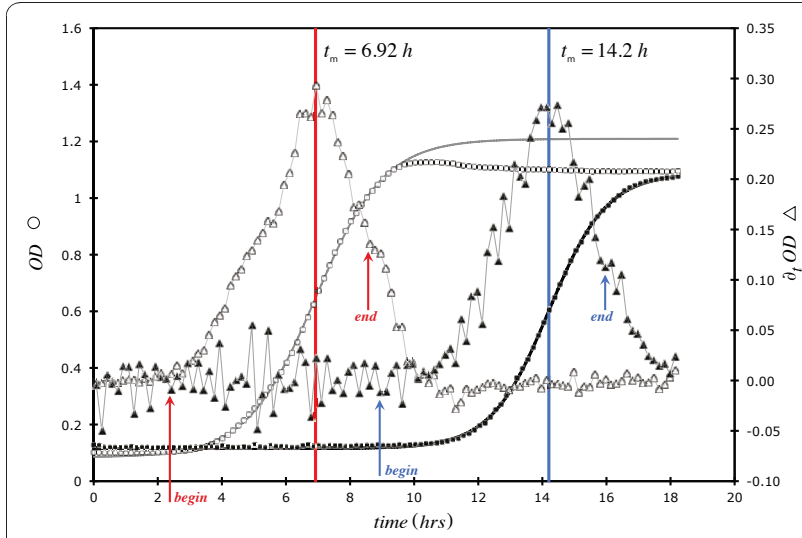

Figure 5 Plot of optical density at $590 \mathrm{~nm}$ (circles) and associated first derivative (OOD, triangles) data associated with S. aureus growth $\left(C_{1} \sim 10^{4} \mathrm{CFU} \mathrm{mL}^{-1}\right)$ at $37^{\circ} \mathrm{C}$ in $\mathrm{BHI}$ broth Open triangles/circles = negative control (beginning/ending arrows in red); closed triangles/circles $\sim 10^{-6} \mathrm{M}$ freeze-dried keratin Nps (beginning/ending arrows in blue); starting bacteria concentration $\sim 10^{4} \mathrm{CFU} \mathrm{mL}^{-1}$

$$
\frac{\mathrm{d} C}{\mathrm{dt}}=C k
$$

in this relation, $k$ is a first order rate constant, $\mathrm{t}$ is the growth time, and $C$ is the bacterial concentration (CFU $\left.\mathrm{mL}^{-1}\right)$. Upon rearrangement, integration between initial $\left(C_{\mathrm{I}}=C_{0} \Phi_{\mathrm{I}}\right)$ and final $\left(C_{\mathrm{F}}\right)$ values of $C$ and solving for $C_{\mathrm{F}}$ we see that

$$
C_{\mathrm{F}}=C_{\mathrm{I}} e^{(\mathrm{t}-T) k} ;
$$

where $T$ is a time translation constant utilized to correct for the observed lag in cell growth (which is typically about 1 hour for our 3 bacterial species). In our usage, we assume that $C_{\mathrm{F}}$ is the cell density at which the relationship between OD and $C$ becomes non-linear, which is about $5 \times 10^{8} \mathrm{CFU} \mathrm{mL} \mathrm{m}^{-1}$ for certain bacilli such as E. coli [23]. $C_{\mathrm{I}}$ was measured by performing a drop plating procedure using 18-24 technical replicates per measurement (to minimize sampling error [30,31]) on the original stationary phase cultures which were diluted and dispensed into 96-well microtitre plates. The parameter $k$ (an apparent first-order rate constant) was determined by curve fitting the $\mathrm{OD}[\mathrm{t}]$ data to Eq. 1 . Expressing Eq. 3 in terms of the time it takes to reach $C_{\mathrm{F}}$ we see that

$$
t=k^{-1} \operatorname{Ln}\left[\frac{C_{\mathrm{F}}}{C_{\mathrm{I}}}\right]+T
$$

We have chosen to express Eq. 4 in terms of $t_{\mathrm{m}}$ which provides Eq. 5 (i.e., the value of $\mathrm{t}$ when $C=C_{\mathrm{F}} \div 2$ and $\left.\mathrm{t}=t_{\mathrm{m}}\right)$

$$
t_{\mathrm{m}}=k^{-1} \operatorname{Ln}\left[\frac{C_{\mathrm{F}}}{2 C_{\mathrm{I}}}\right]+T .
$$

Knowing $t_{\mathrm{m}}, k, C_{\mathrm{I}}$, and $C_{\mathrm{F}}$ we can estimate $T$. We calculate a corrected $T\left(T_{\text {corr }}\right)$ by merely assuming that the negative control in each set of $N p$ experiments has a $T=$ $1 \mathrm{hr}$. One common method [32] for determining $T$ is by curve-fitting log-transformed plate count data with respect to time to another type of sigmoidal growth curve known as the Gompertz Equation (e.g., $\operatorname{Ln}[C]=\alpha$ $\operatorname{Exp}[-\operatorname{Exp}[\beta-\gamma t]]+\delta)$ where $T$ is a function of both $\beta$ and $\gamma$ : i.e., $T=[\beta-1] \gamma^{-1} \pm$ a propagated error term $[32,33]$. This kinetic method is very time consuming and proves difficult to observe a large number of treatments due to the time involved in collecting samples, plating, etc. However, using this manual technique we have found that both E. coli $\mathrm{O} 157: \mathrm{H} 7$ and Salmonella Typhimurium show similar lag times $(T \sim 1-1.5 \mathrm{hr})$ to $S$. aureus $(T=$ $1.4 \pm 0.49 \mathrm{hr}$ ) but somewhat larger $k$ (i.e., a shorter $\tau)$. 
Since the apparent effect of both keratin- and citratecapped $N p$ s on $t_{\mathrm{m}}$ could also result from a change in $C_{\mathrm{I}}$ (i.e., cell death) we have estimated the probability $\left(P_{+}\right)$for any growth occurring in the 96-well plates, assuming only changes in $C_{\mathrm{I}}(e . g$., with a $T$ fixed at $1 \mathrm{hr}$ )

$$
P_{+}=1-\operatorname{Exp}\left[-C_{\mathrm{I}, \mathrm{calc}} V\right]
$$

and

$$
C_{\mathrm{I}, \mathrm{calc}}=\frac{C_{\mathrm{F}} \operatorname{Exp}\left[k\left(1-t_{\mathrm{m}}\right)\right]}{2} .
$$

$C_{\mathrm{F}}$ is iteratively evaluated in order to make $C_{\mathrm{I}}$, obs (negative control; based on enumeration of $C_{0}$ using the

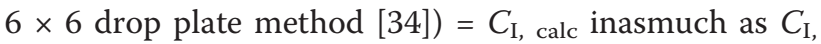
obs, $k$ and $t_{\mathrm{m}}$ have all been calculated empirically. Eq. 6 is a well-known expression for calculating the probability of observing positive growth (turbidity). When multiplied by $n$, the number of growth observations, Eq. 6 can be used to calculate the number of positives out of $n$ observations of growth in most probable number (MPN) determinations. Briefly, Eq. $\mathbf{6}$ can be produced when the partial first derivative of the binomial probability distribution function $\left(P\left[C_{\mathrm{I}}\right]\right)$ with respect to $C_{\mathrm{I}}$ is normalized to itself (i.e., $\partial_{C_{\mathrm{I}}} P\left[C_{\mathrm{I}}\right] \div P\left[C_{\mathrm{I}}\right]$ ), set to zero, and the number of positive growth responses $(p)$ calculated. When both sides of this relationship are divided by $n$, Eq. 6 is produced. Eq. 7 is just a rearrangement of Eq. 5 solving for $C_{\mathrm{I}}$ and assuming $T=1 \mathrm{hr}$.

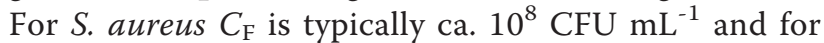
the Gram-negative organisms, $C_{\mathrm{F}} \sim 5 \times 10^{8}$ [23]. Thus, in essence, $P_{+}$is the probability that the observed changes in $t_{\mathrm{m}}$ could be due to perturbations in the $C_{\mathrm{I}}$ in the presence of the Nps.

\section{Statistical Tests of Significance}

In this work a "randomized complete block" [35] (also known as the "randomized block" [36]) design was used and replication was based upon either position on a plate (Table 1) or culture (all other reported experiments: i.e., a major source of variation in microbiology is the starting culture). We also used the well-known Tukey or $q$-value-based multiple range test [35 p 444, 36 appendix $\mathrm{p}$ 64]. For this multiple range test the $q_{0.05}$ is multiplied by $\sqrt{E M S \div b}=s_{\bar{x}}$ (EMS = error mean square; $b=$ number of blocks or true replicates encompassed by each treatment mean $\bar{x}$ ). The $q$-test is more stringent than many multiple range tests such as the Student's $t$. All figures presenting growth parameter data are provided with the observed average $t_{\mathrm{m}}$ or $T_{\text {corr }}$ (average of 3 experiments) displayed as $\pm q_{0.05} s_{\bar{x}} \div 2$.

\section{Acknowledgements}

All funding was from ARS base funds associated with Current Research Information System (CRIS) Project Number 1935-42000-058-00 D (Integrated Biosensor-Based Processes for Multipathogenic Analyte Detection) and 193542000-020-00 D (Wool and Keratin from Wool for Bio-Based Value-Added Products)

\section{Author details}

'Molecular Characterization of Foodborne Pathogens Research Unit, Eastern Regional Research Center, Agricultural Research Service, U. S. Department of Agriculture, 600 East Mermaid Lane, Wyndmoor, PA 19038 USA. ${ }^{2}$ PPG Industries, Pittsburgh, PA USA.

\section{Authors' contributions}

PI designed all of the experiments (with input from CC and JM), performed all calculations and statistical analyses, participated in running most of the experiments and drafted the manuscript. JM performed all the Np syntheses and characterizations and took part performing the various bioassays as well as helping to draft the manuscript. LN carried out all the $C_{\text {I }}$ enumeration assays and performed many of the OD growth experiments and helped draft the manuscript. YH, AG, and CC assisted in certain aspects of the experiments as well as drafting the manuscript. All authors read and approved the final manuscript.

\section{Competing interests}

The authors declare that they have no competing interests.

Received: 16 September 2010 Accepted: 21 December 2010 Published: 21 December 2010

\section{References}

1. Daniel MC, Astruc D: Gold nanoparticles: assembly, supramolecular chemistry, quantum-size-related properties, and applications toward biology, catalysis, and nanotechnology. Chem Rev 2004, 104:293-346.

2. Sau TK, Pal A, Jana NR, Wang ZL, Pal T: Size controlled synthesis of gold nanoparticles using photochemically prepared seed particles. J Nanopart Res 2001, 3:257-261.

3. Xia Y, Yang P, Sun Y, Wu Y, Mayers B, Gates B, Yin Y, Kim F, Yan H: Onedimensional nanostructures: synthesis, characterization, and applications. Adv Mater 2003, 15:353-389.

4. Jin R, Cao C, Hao E, Métraux GS, Schatz GC, Mirkin CA: Controlling anisotropic nanoparticle growth through plasmon excitation. Nature 2003, 425:487-490.

5. Jin R, Cao Y, Mirkin CA, Kelly KL, Schatz GC, Zheng JG: Photoinduced Conversion of Silver Nanospheres to Nanoprisms. Science 2001, 294:1901-1903.

6. Kelly KL, Coronado E, Zhao LL, Schatz GC: The optical properties of metal nanoparticles: the influence of size, shape, and dielectric environment. J Phys Chem B 2003, 107:668-677.

7. Xue C, Chen X, Hurst SJ, Mirkin CA: Self-assembled monolayer mediated silica coating of silver triangular nanoprisms. Adv Mater 2007, 19:4071-4074.

8. Xue C, Mirkin CA: pH-switchable silver nanoprism growth pathways. Angew Chem Int Ed 2007, 46:2036-2038.

9. Scott RWJ, Wilson OM, Crooks RM: Synthesis, characterization, and applications of dendrimer-encapsulated nanoparticles. J Phys Chem B 2005, 109:692-704.

10. Eustis S, El-Sayed MA: Why gold nanoparticles are more precious than pretty gold: Noble metal surface plasmon resonance and its enhancement of the radiative and nonradiative properties of nanocrystals of different shapes. Chem Soc Rev 2006, 35:209-217.

11. Gogotsi Y: Nanomaterials Handbook CRC, Boca Raton, Florida; 2006.

12. Rosi NL, Mirkin CA: Nanostructures in biodiagnostics. Chem Rev 2005, 105:1547-1562.

13. Elechiguerra JL, Burt JL, Morones JR, Camacho-Bragado A, Gao X, Lara HH, Yacaman MJ: Interaction of silver nanoparticles with HIV-1. J Nanobiotechnol 2005, 3:6

14. Tan S, Erol M, Suklushvili S, Du H: Substrates with discretely immobilized silver nanoparticles for ultrasensitive detection of anions in water using surface-enhanced raman scattering. Langmuir 2008, 24:4765-4771. 
15. Lok C-N, Ho C-M, Chen R, He Q-Y, Yu W-Y, Sun H, Tam PK-H, Chiu J-F, Che C-M: Proteomic analysis of the mode of antibacterial action of silver nanoparticles. J Proteome Res 2006, 5:916-924.

16. Chopra I: The increasing use of silver-based products as antimicrobial agents: a useful development or a cause for concern? I Antimicrob Chemother 2007, 59:587-590.

17. Gulrajani ML, Gupta D, Periyasamy S, Muthu SG: Preparation and application of silver nanoparticles on silk for imparting antimicrobial properties. J Appl Polym Sci 2008, 108:614-623.

18. Lee W-F, Tsao K-T: Preparation and properties of nanocomposite hydrogels containing silver nanoparticles by ex situ polymerization. J Appl Polym Sci 2006, 100:3653-3661.

19. Tarimala S, Kothari N, Abidi N, Hequet E, Fralick J, Dai LL: New approach to antibacterial treatment of cotton fabric with silver nanoparticle-doped silica using sol-gel process. J Appl Polym Sci 2006, 101:2938-2943.

20. Jiang H, Manolache S, Wong ACL, Denes FS: Plasma-enhanced deposition of silver nanoparticles onto polymer and metal surfaces for the generation of antimicrobial characteristics. J Appl Polym Sci 2004, 93:1411-1422

21. Neal AL: What can be inferred from bacterium-nanoparticle interactions about the potential consequences of environmental exposure to nanoparticles? Ecotoxicology 2008, 17:362-371.

22. Pal S, Tak YK, Song JM: Does the antibacterial activity of silver nanoparticles depend on the shape of the nanoparticle? A study of the Gram-negative bacterium Escherichia coli. Appl Environ Microbiol 2007 73:1712-1720.

23. Irwin P, Nguyen L-HT, Paoli GC, Chen C-Y: Evidence for a bimodal distribution of Escherichia coli doubling times below a threshold initial cell concentration. BMC Microbiol 2010, 10:207.

24. Brewster J: A simple micro-growth assay for enumerating bacteria. J Microbiol Meth 2002, 53:77-86.

25. Liu X, Atwater M, Wang J, Huo Q: Extinction coefficient of gold nanoparticles with different sizes and different capping ligands. Colloids and Surfaces B: Biointerfaces 2007, 58:3-7.

26. Valiunas V, Manthey D, Vogel R, Willecke K, Weingart R: Biophysical properties of mouse connexin30 gap junction channels studied in transfected human HeLa cells. J Physiol 1999, 519:631-644.

27. Irwin $\mathrm{P}$, Damert $\mathrm{W}$, Doner $\mathrm{L}$ : Curve fitting in nuclear magnetic resonance: illustrative examples using a spreadsheet and microcomputer. Concepts Magn Reson 1994, 6:57-67.

28. Balagadde F, You L, Hansen C, Arnold F, Quake S: Long-Term Monitoring of Bacteria Undergoing Programmed Population Control in a Microchemostat. Science 2005, 309:137-140.

29. Lopez S, Prieto M, Dijkstra J, Dhanoa M, France J: Statistical evaluation of mathematical models for microbial growth. Int I Food Microbiol 2004, 96:289-300.

30. Irwin $\mathrm{P}$, Nguyen $\mathrm{L}-\mathrm{H}$, Chen C-Y: Binding of nontarget microorganisms from food washes to anti-Salmonella and anti-E. coli 0157 immunomagnetic beads: most probable composition of background Eubacteria. Anal Bioanal Chem 2008, 391:515-524.

31. Irwin PL, Nguyen L-H, Chen C-Y: The relationship between purely stochastic sampling error and the number of technical replicates used to estimate concentration at an extreme dilution. Anal Bioanal Chem 2010, 398:895-903

32. Zwietering $\mathrm{MH}$, Jongenburger I, Rombouts $\mathrm{FM}$, van't Riet $\mathrm{K}$ : Modeling of the bacterial growth curve. App Environ Microbiol 1990, 56:1875-1881.

33. Beers Y: Introduction to the Theory of Error Addison-Wesley Publishing Company, Inc., Reading, MA; 1958, 29-30.

34. Chen C-Y, Nace GW, Irwin PL: A $6 \times 6$ drop plate method for simultaneous colony counting and MPN enumeration of Campylobacter jejuni, Listeria monocytogenes, and Escherichia coli. J Microbiol Methods 2003, 55:475-479.

35. Steele RGD, Torrie JH: Principles and procedures of statistics McGraw-Hill, 1960, New York;132.

36. Zar JH: Biostatistical Analysis Prentice Hall, 1999, Upper Saddle River, NJ;250.

doi:10.1186/1477-3155-8-34

Cite this article as: Irwin et al: Antimicrobial activity of spherical silver nanoparticles prepared using a biocompatible macromolecular capping agent: evidence for induction of a greatly prolonged bacterial lag phase. Journal of Nanobiotechnology 2010 8:34.

\section{Submit your next manuscript to BioMed Central and take full advantage of:}

- Convenient online submission

- Thorough peer review

- No space constraints or color figure charges

- Immediate publication on acceptance

- Inclusion in PubMed, CAS, Scopus and Google Scholar

- Research which is freely available for redistribution 